\title{
Rancangan Fasilitas Pusat Komunitas Film Indie di Surabaya
}

\author{
Rinda Amalia Aisyah ${ }^{1}$, Amir Mukmin Rachim², Siti Azizah ${ }^{3}$ \\ 1,2,3Jurusan Arsitektur, Fakultas Teknik Sipil dan Perencanaan, Institut Teknologi Adhi Tama \\ Surabaya \\ Email :1 rindamalia15@gmail.com, 2amirmr@itats.ac.id
}

\begin{abstract}
The development of Surabaya in a film by film festival event has been conducted, one of them is Indie film, showing the potential owned by Surabaya. On one side the facilities for the Indie film and Indie film community in Surabaya is currently still minim. This condition makes the Indie film's enthusiast have difficulty in getting to know more about Indie film. The problem is how to make the design of Indie film community center facilities. The methodology of the study used is the descriptive-qualitative analysis method. The design is expected to give indie film creators and indie film enthusiasts the adequate facilities to be more creative. Thus, it can increase the interest of film enthusiasts.
\end{abstract}

Keywords: facilities, center, community, Indie film

\begin{abstract}
Abstrak. Berkembangnya kota Surabaya di bidang perfilman salah satunya film Indie dengan acara festival perfilman yang pernah diadakan di kota menunjukkan potensi yang dimiliki kota Surabaya. Di satu sisi fasilitas untuk film Indie dan komunitas film Indie yang ada di kota Surabaya saat ini masih sangat minim. Kondisi tersebut membuat orang yang tertarik dengan film Indie mengalami kesulitan untuk mengenal lebih jauh tentang film Indie. Permasalahannya adalah, Bagaimana membuat rancangan fasilitas pusat komunitas film Indie. Metode penelitian yang digunakan adalah metode analisis deskriptif kualitatif. Rancangan fasilitas ini diharapkan dapat memberi fasilitas yang memadai bagi para kreator film Indie dan penggemar film Indie untuk lebih bebas berkarya sehingga dapat menambah minat bagi penggemar film.
\end{abstract}

Kata Kunci: fasilitas, pusat, komunitas, film Indie

\section{Pendahuluan}

Surabaya sebagai ibu kota Jawa Timur dan salah satu kota besar di Indonesia tentunya juga memiliki potensi yang besar. Selain itu, kota Surabaya dinilai sebagai salah satu kota kreatif karena banyaknya insan kreatif yang berasal dari kota tersebut. perencanaan dan rancangan Pusat Komunitas Film Indie di Surabaya sebagai fasilitas yang mewadahi kegiatan komunitas film Indie di Surabaya, agar memiliki fungsi produktif dan dapat dijadikan tempat berkumpulnya para pecinta film Indie. Bangunan juga harus mevisualisasikan fasad yang menarik dan sesuai dengan fungsi bangunan, mengolah ruang-ruang bangunan agar dapat memfasilitasi seluruh kegiatan komunitas film Indie yang dapat menunjang seluruh kegiatan pada bangunan yang akan dirancang, dan cara mengatur sirkulasi pada tapak sehingga segala fasilitas dalam perancangan dapat dinikmati oleh pengunjung.

Rancangan ini dimaksudkan untuk memberikan wadah komunitas dan pecinta film Indie, serta bertujuan agar terpenuhi keinginan komunitas Indie akan sebuah gedung pertunjukan film Indie yang kedepannya diharapkan dapat menjadi salah satu hiburan alternatif dalam bidang film Indie di Surabaya.

\subsection{Tinjauan Pustaka}

Film Indie adalah media pembebasan, karya yang bisa dipakai untuk mengungkapkan berbagai rasa dari para pembuatnya. Istilah film pendek (saat itu diformulasikan) tidak dibatasi pada format dan panjangnya film, tetapi mengarah pada pencarian bentuk alternatif dari media itu sendiri (Prakosa, 1997). Kegiatan di komunitas film bisa beragam, misalnya tentang produksi film, pemutaran dan diskusi yang diselenggarakan secara terbuka. Beberapa komunitas ada yang mengkhususkan diri hanya pada pemutaran film-film pendek dengan memanfaatkan tempat dan ruang alternatif. Festival film rutin diadakan, ruang-ruang alternatif semakin gencar menjaring komunitas pembuat film (sampai merekrut mereka dalam satu atap), dan para pembuat film amatir yang kadang 
hanya bermodal ide kenekatan, video kamera, dan komputer dengan software editing yang sederhana, mereka semakin berani memproduksi film (Barry, 2018).

Dalam mewujudkan identitas pengguna bangunan yang mewadahi komunitas film indie, maka, dapat menggunakan desain arsitektur metafora. Abel (1997) menyebutkan bahwa arsitektur metafora adalah mengidentifikasi suatu bangunan arsitektural dengan pengandaian sesuatu yang abstrak sehingga setiap pengamat akan mempunyai persepsi masing-masing sesuai dengan persepsi yang timbul pada saat pertama kali melihat bangunan tersebut. Melalui metafora, imajinasi perancang bisa diuji dan dikembangkan. Mereka yang memiliki daya imajiasi yang tinggi tidak akan mengalami kesulitan dalam menggunakan metafora, bahkan metafora akan semakin memperluas dan memperdalam daya imajinasi mereka.

Ruang-ruang publik menjadi sering digunakan oleh berbagai lapisan masyarakat, desain ruang harusnya menerapkan sifat adaptasi dimana desain akan mengarahkan perilaku atau kegiatan pengguna sesuai yang diharapkan sehingga akan tetap menimbulkan ketertiban, kelancaran, dan kemudahan aktifitas, sedangkan untuk ruang-ruang yang membutuhkan kenyamanan yang lebih tinggi, maka desain difokuskan untuk memperhatikan kenyamanan dan kebutuhan pengguna (Azizah, 2013).

\subsection{Metode Penelitian}

Metode penelitian yang digunakan dalam adalah metode penelitian deskriptif kualitatif, yang diawali dengan menganalisa isu objek rancangan maupun isu yang terjadi di lapangan. Isu yang sudah terkumpul maka akan ditemukan permasalahan yang nantinya akan dicarikan solusi yang tepat. Kemudian langkah berikutnya adalah menganalisis data studi kasus, tapak dan program ruang ini menggunakan Metode kualitatif dan survei studi kasus lapangan dan literatur. Setelah dianalisis tahap selanjutnya adalah menganalisa data dan akan menghasilkan konsep desain beserta transformasi konsepnya. Lalu akan dikembangkan kembali menjadi desain akhir.

\section{Pembahasan}

Pembahasan akan menjelaskan perencanaan konsep rancangan, mulai dari objek studi kasus, telaah terhadap lokasi rancangan, penyusunan konsep rancangan, hingga gambaran hasil konsep rancangan. Hasil observasi studi literatur mengambil Objek Busan Sinema Center yang berlokasi di Busan, Korea Selatan dan UFA Cinema Center yang berlokasi di St. Petersburger Straße 24a, 01069 Dresden, Germany. Untuk studi lapangan menggunakan objek teater IMAX Keong Emas TMII, Jakarta Timur dan CGV Marvel City Surabaya (Gambar 1, Gambar 2, Gambar 3, dan Gambar 4).
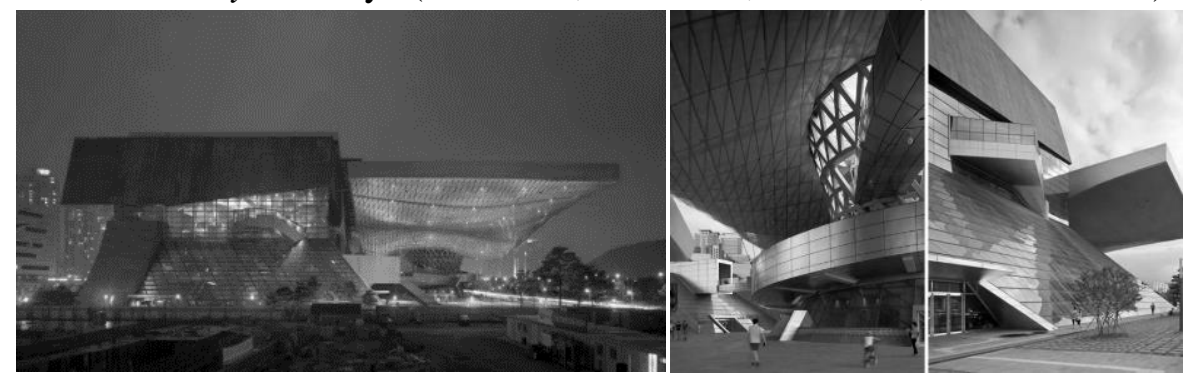

Gambar 1. Busan Cinema Center

Sumber : https://www.designboom.com/architecture/coop-himmelblau-busan-cinemacenter-2/) Sabtu, 8 desember 2019 / jam 19.30 WIB

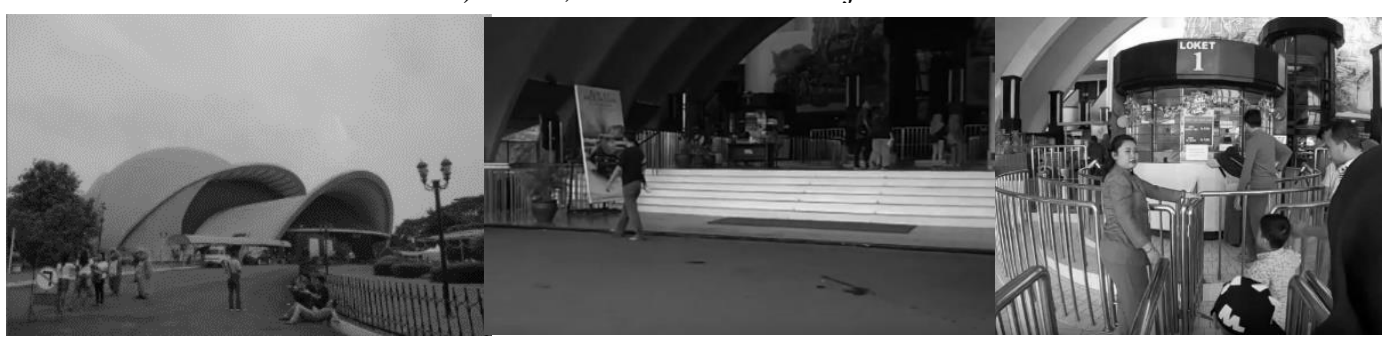

Gambar 2. UFA Cinema Center

Sumber : https://www.designboom.com/architecture/coop-himmelblau-busancinema-center-2/) Sabtu, 8 desember 2019/ jam 19.30 WIB 

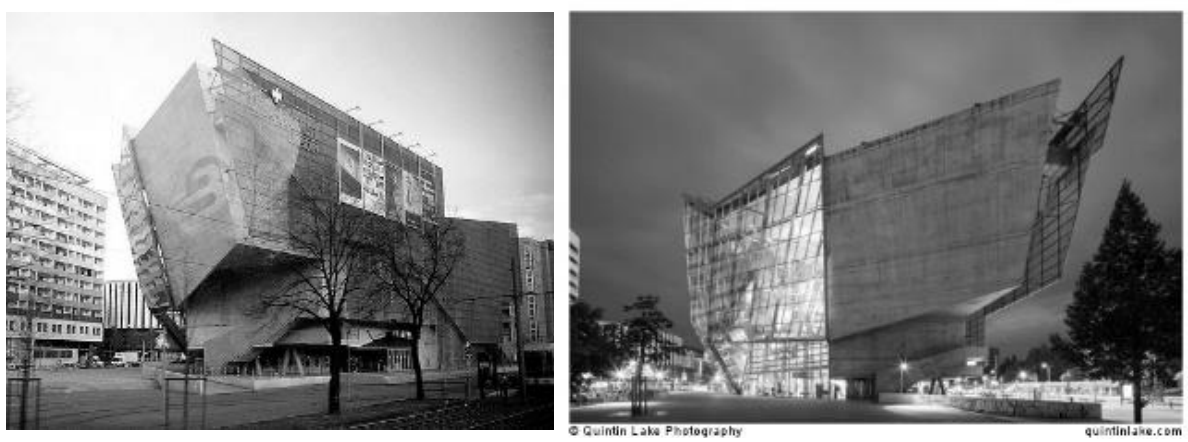

Gambar 3. Teater IMAX Keong Emas TMII

Sumber : Dokumentasi Pribadi, 09 Nopember 2019

Semua objek studi kasus terletak di Kawasan perkotaan sehingga memiliki akses yang mudah. Segi tampilan bangunan sudah dapat menunjukkan ciri khasnya tersendiri. Segi ruang lebih difokuskan pada area sirkulasi dan merancang ruang sesuai dengan kebutuhan pada masing-masing ruang tersebut. Hasil ringkasan dari studi kasus dapat dijadikan acuan untuk hasil rancangan yang sesuai dengan kebutuhan

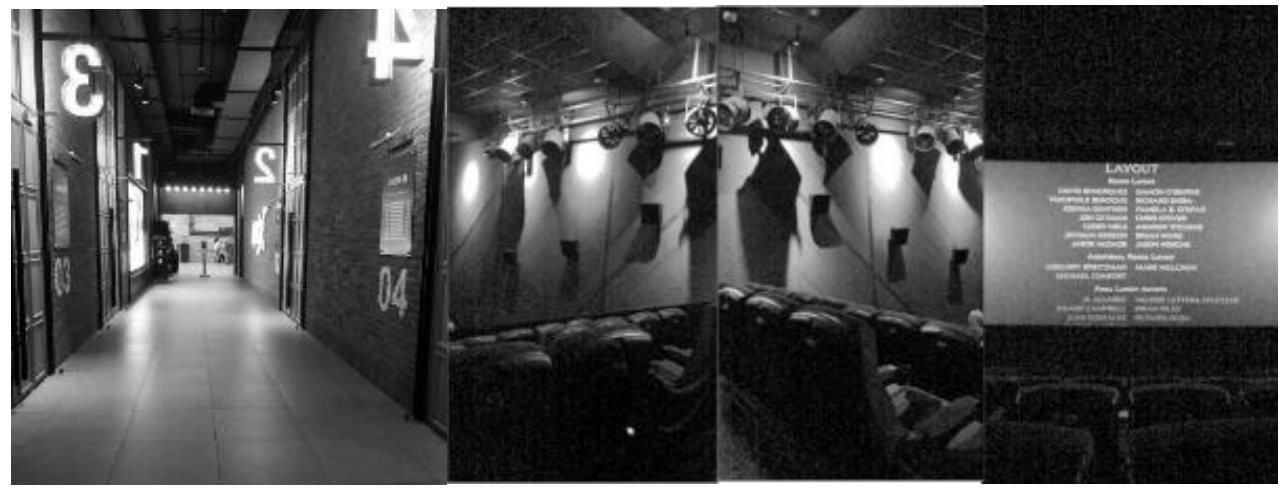

Gambar 4. CGV Marvel City Surabaya

Sumber : Dokumentasi Pribadi, 23 Oktober 2019
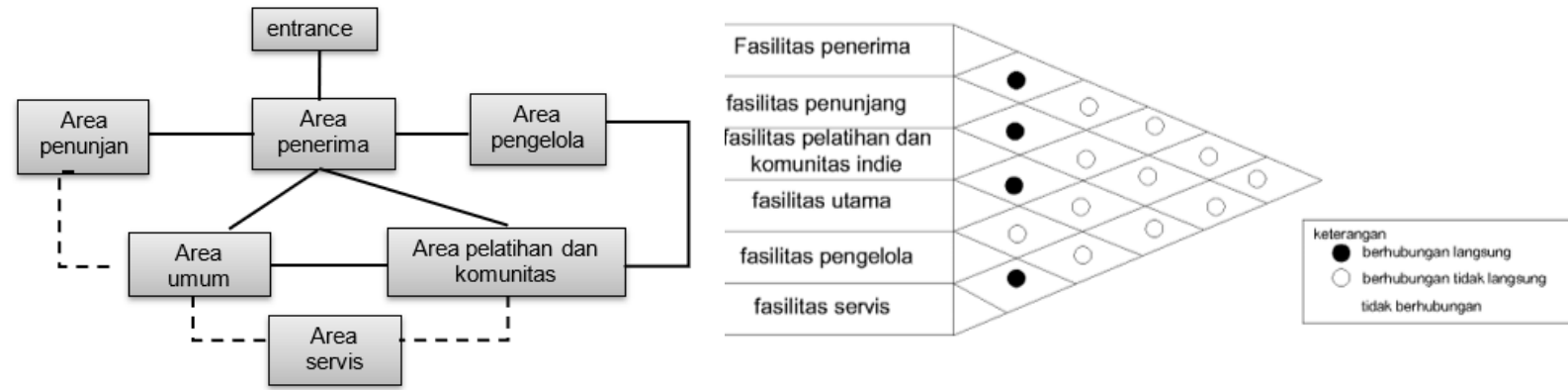

Gambar 5. (kiri) diagram organisasi makro, (kanan) diagram hubungan ruang Sumber : Dokumentasi Pribadi, 23 Oktober 2019

Lokasi lahan berada di Jl. Bukit Darmo Boulevard, Surabaya-Jawa Timur dengan ukuran kurang lebih 2 hektar. Kondisi eksisting lahan berada dekat dengan pemukiman, sarana Pendidikan, dan sarana hiburan sehingga lokasi dapat diakses dariberbagai kalangan. 


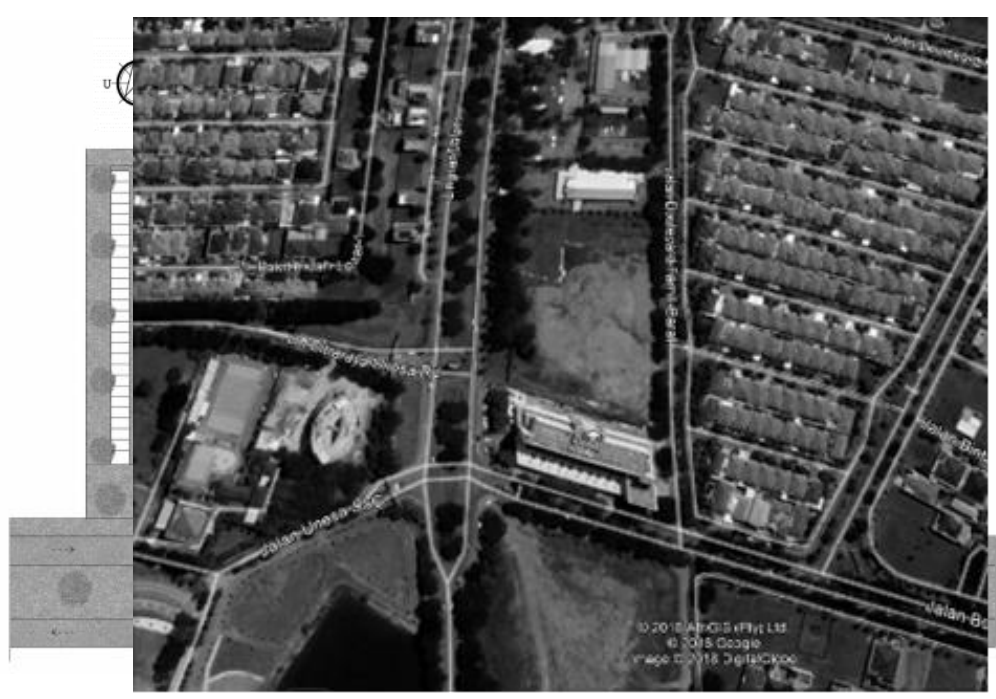

Gambar 6. Lokasi Site

Sumber : google earth, 23 Oktober 2019

Konsep mikro tatanan lahan yang digunakan adalah "terarah", mengingat karakter Indie yang cenderung tidak selalu mengikuti aturan yang ada, sehingga konsep terarah dapat menciptakan Sirkulasi yang mudah dipahami agar tercapai sirkulasi yang mudah bagi pengunjung dan pegawai serta menambah kenyamanan. Zona Pada zona A terdapat fasilitas bioskop, ruang pameran, convention hall, cafetaria, dan toko souvenir yang berada pada zona publik. Pengunjung dapat memanfaatkan area drop off dengan sebuah sculpture yang berbentuk roll film sehingga bisa digunakan sebagai penanda bagi pengunjung. Pada zona B akan memasuki area semi privat, area tersebut terdapat ruang pelathihan dan ruang komunitas yang akan digunakan oleh komunitas Indie. Zona $\mathrm{D}$ adalah area semi publik yang terdapat ruang perpustakaan dan koleksi film. Zona $\mathrm{C}$ adalah area servis yang merupakan area privat sehingga pengunjung tidak boleh langsung memasuki area tersebut. Zona $\mathrm{D}$ adalah area taman parkir. Vegetasi selain untuk peneduh, digunakan juga sebagai pembatas sehingga semakin memperjelas batas tapak dengan Kawasan di sekitar lahan.

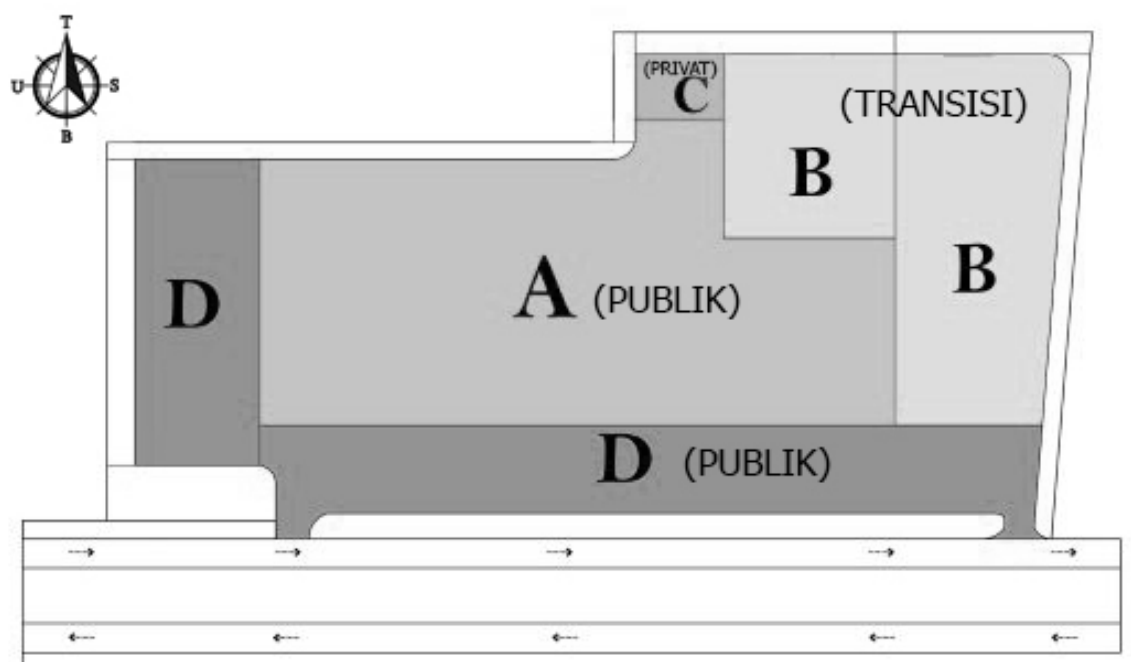

Gambar 8. Transformasi tatanan lahan, selanjutnya dianalisis Menjadi tatanan Lay Out plan Sumber : Dokumentasi analisis pribadi

Taman parkir yang dipisahkan antara area pengunjung dan pengelola ditambah dengan elemen tanaman peneduh untuk kenyamanan pengguna. Pencapaian publik, zona transisi, dan zona privat diterapkan agar memudahkan akses. Untuk bioskop dan ruang pameran berada di zona public 
yang dekat dengan area drop off dan lahan parkir untuk kemudahan akses bagi pengunjung. Sedangkan untuk studio film berada di zona privat berbeda untuk mengurangi kebisingan dan digunakan oleh komunitas film Indie

Konsep mikro bentuk "atraktif". Konsep atraktif akan memunculkan suatu rancangan bangunan yang atraktif dan mempunyai ciri khas tersendiri sehingga bentuk massa bangunan jauh dari kesan atau suasana monoton. Bentuk metafora diterapkan brntuk bangunan persegi yang menyerupai bentuk pixel. Menggunakan secondary skin yang akan menciptakan sebuah pola roll film yang biasa dijadikan simbol dalam dunia perfilman. Bagian fasad menggunakan warna yang terinspirasi dari roll film yaitu penggunaan dua warna terang dan gelap

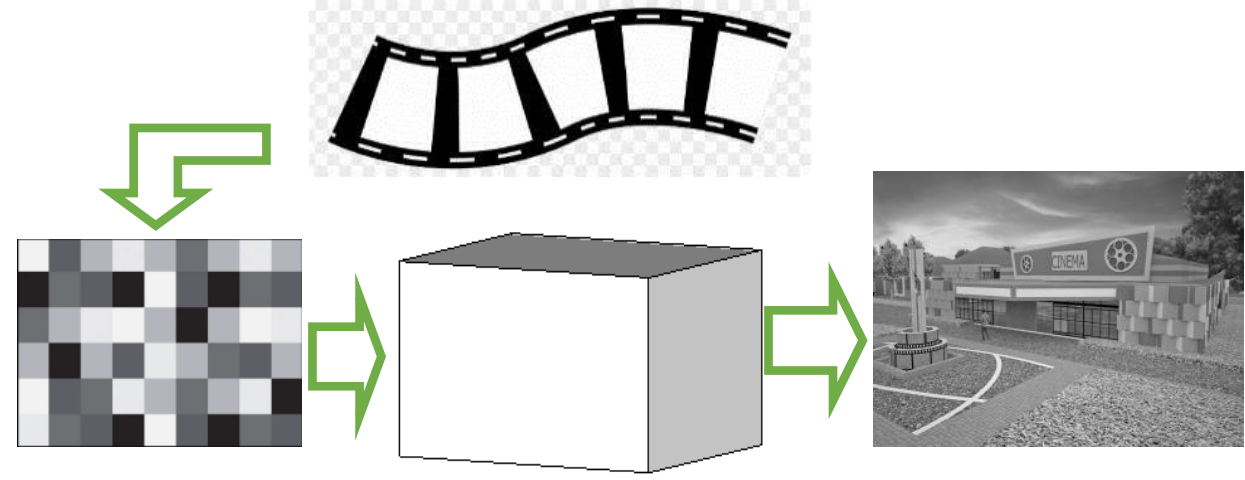

\section{Gambar 9. Transformasi Bentuk Dari bentuk dasar roll film, dianalisis menjadi bentuk bangunan \\ Sumber : Dokumentasi analisis pribadi}

Konsep mikro ruang "adaptif" yaitu merancang ruang sesuai dengan fungsi kebutuhan di dalam ruangan tersebut, sehingga memberikan kenyamanan yang sesuai yang diinginkan. Konsep ruang adaptif akan menggunakan material yang berbeda, yaitu, menyesuaikan fungsi ruang yang akan digunakan. Khusus untuk studio film dan bioskop membutuhkan material peredam suara supaya mengurangi suara bising di dalam ruangan, untuk ruang pameran dibutuhkan sirkulasi yang luas untuk kenyamanan pengguna.

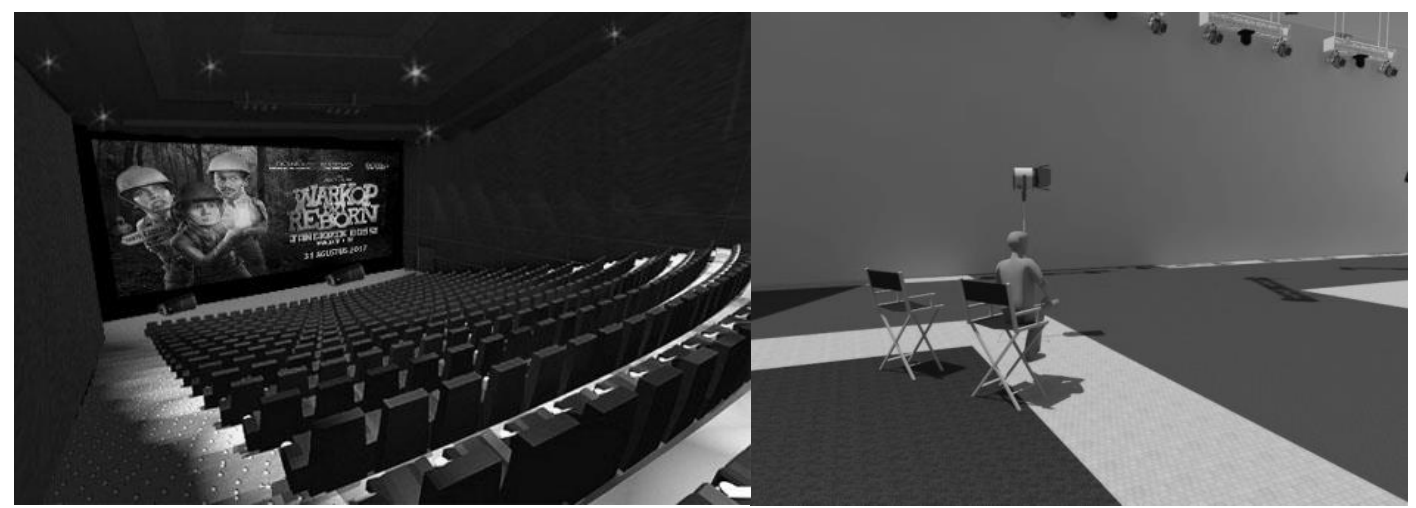

Gambar 10. Transformasi ruang Ruang bioskop dirancang dengan menggunakan material/warna yang kontras. Pada bagian plafond dan didnding dilengkapi dengan peredam suara Sumber : Dokumentasi analisis pribadi

\section{Kesimpulan}

Rancangan fasilitas Pusat Komunitas film Indie ini akan memberikan wadah untuk para komunitas Indie dan menghadirkan sinema Indie, dimana dapat dimanfaatkan sebagai sarana hiburan yang bisa dinikmati mulai dari warga Surabaya hingga di luar Surabaya.

Ada banyak kreator film seniman yang sangat berbakat di luar sana, yang mungkin belum dapat kesempatan untuk menunjukkan karyanya entah karena organisasi yang kurang, wadah untuk 
menyalurkan bakat, atau fasilitas yang belum memadahi. Dengan membangun pusat sinema Indie maka akan meningkatkan peluang kreator - creator film Indie. Fasilitas pusat komunitas sinema Indie juga dapat memberkan kesempatan untuk orang awam untuk mengetahui bahwa film Indie tidak hanya sebagai film 2 dimensi yang bergerak. Pengunjung juga bisa mengetahui perjalanan proses dalam film Indie, dan berharap pengunjung kedepannya bisa lebih mengapresiasi film Indie.

\section{Referensi}

Abel, Chris. (1997). Architecure and Identity, Great Britain: Architectural Press.

Azizah, Siti. (2013). Surabaya. Kaitan Desain Ruang dengan Perilaku Pengguna pada Bangunan Publik. Seminar Nasional Sains dan Teknologi Terapan (SNTEKPAN 2013) - Pentingnya Peranan Perguruan Tinggi Dalam Pengembangan Inovasi Teknologi Demi Kemandirian Bangsa. Surabaya: ITATS.

Barry, Syamsul. (2018). Fenomena Komunitas Film. Kalatanda Jurnal Desain Grafis Dan Media Kreatif

Prakosa, G. (1997). Film Pinggiran. Jakarta: FFTV-IKJ Press. 